\title{
A MELANCOLIA DO RISO: VIAGENS IMAGINÁRIAS DE UM NARRADOR
}

\section{LA MELANCOLÍA DE LA RISA: VIAJES IMAGINARIAS DE UN NARRADOR}

\author{
Eduarda da Matta"
}

RESUMO: "É certo que as cores influem sobre nós a ponto de nos alegrarem ou de nos entristecerem, segundo os seus tons.” Esse trecho foi retirado do romance Viagem à roda do meu quarto, de Xavier de Maistre (2008, p. 26), e é à sua roda, por assim dizer, que se findará o presente artigo. Faz-se presente, em boa parte da narrativa, ora muito evidente, ora implícita apenas nas entrelinhas, uma forte melancolia. Esta, no entanto, é decorrente de um fato externo à narração, o encarceramento domiciliar do seu autor, Xavier. O livro possui vários pontos interessantes a serem discutidos, porém, o objetivo deste artigo é centrar-se na questão da melancolia, percebida através de seu narrador e suas teorias, na soma das estratégias de construção do romance, que mostram a melancolia do riso nas viagens imaginárias de um narrador, e faz com que Viagem à roda do meu quarto seja a viagem de cada um dos leitores, quando adentram pelos bosques da ficção.

Palavras-chave: Xavier de Maistre. Melancolia. Narrador.

RESUMEN: "Es cierto que los colores influyen sobre nosotros al punto de alegrarnos o de entristecernos, según sus tonos." Este trozo fue retirado de la novela Viagem à roda do meu quarto, de Xavier de Maistre. (2008, p.26, traducción nuestra), y es a su rueda, por así decirlo, que se constituirá el presente artículo. Se hace presente, en buena parte de la narrativa, por veces implícita solo en las entre hileras, una fuerte melancolía. Esta, sin embargo, es decurrente de un hecho externo a la narración, el encarcelamiento domiciliar de su autor, Xavier. El libro posee varios puntos interesantes a ser discutidos, pero el objetivo de este artículo se foca en la cuestión de la melancolía, percibida a través de su narrador y sus teorías, en la suma de las estrategias de construcción de la novela, que muestran la melancolía de la risa en las viajes imaginarias de un narrador, y hace con que Viagem à roda do meu quarto sea el viaje de cada uno de los lectores, cuando adentran por los bosques de la ficción.

Palabras-clave: Xavier de Maistre. Melancolía. Narrador.

\footnotetext{
"Professora do Departamento de Letras da UNICENTRO, Campus de Irati, PR. Graduada em Letras Português/ Espanhol pela UEPG. Mestre em Estudos Literários pela UFPR. Doutoranda em Estudos Literários pela UFPR. E-mail: dudaerdm@hotmail.com
} 
Por quarenta e dois dias, Xavier de Maistre esteve recluso em seu quarto, em prisão domiciliar, tempo em que escreveu o livro. Esse fato não é dito no romance, mas o narrador, em certos momentos, dá alguns indícios do motivo pelo qual não pode sair do quarto. Nós, leitores, ao conhecermos um pouco da vida do autor, subentendemos que se trata de um acontecimento biográfico, e não apenas ficcional. Usando-se da metalinguagem em um discurso direto com o leitor, o narrador explica que há tempos gostaria de escrever esse romance, e não foi por conta da situação que se encontra que o fez:

Antes de ir mais longe, quero destruir uma dúvida que poderia ter se introduzido no espírito de meus leitores.

Não desejava, por nada nesse mundo, que suspeitassem ter eu empreendido esta viagem unicamente por não saber o que fazer e forçado, de qualquer maneira, pelas circunstâncias: aqui afirmo, e juro por tudo o que me é caro, que já tinha intenção de empreendê-la muito tempo antes do acontecimento que me fez perder a liberdade durante quarenta e dois dias. Esta reclusão forçada foi apenas a ocasião de me pôr a caminho mais cedo. (MAISTRE, 2008, p. 52-53).

Com esse trecho, além de perceber a atenção que o narrador dá ao discorrer sobre a confecção do livro, a leve explicação acerca da privação da sua liberdade, e o uso da metalinguagem, fica evidente a preocupação que este tem com o leitor. O discurso é muito cuidadoso, cauteloso, explicativo, como se o narrador precisasse do leitor mesmo no momento de construção da obra. No início do romance, em uma das primeiras intervenções, o narrador faz um convite ao leitor:

Sigam-me todos a quem uma mortificação do amor, uma negligência da amizade, retém no seu quarto, longe da pequenez e da perfídia dos homens. Que todos os infelizes, doentes e entediados do universo me sigam! - Que todos os preguiçosos levantem-se em massa! E vós todos que acalentais no espírito sinistros projetos de reforma ou de retirada por qualquer infidelidade; vós que, numa alcova, renunciais ao mundo por toda a vida; amáveis anacoretas de uma noite, vinde também: abandonai, crede-me, essas negras ideias; estais perdendo um instante para o prazer sem ganhar nenhum para a sabedoria: condescendei em acompanhar-me na minha viagem. Seguiremos por pequenas jornadas, rindo, ao longo do caminho, dos viajantes que viram Roma e Paris. - Nenhum obstáculo poderá deter-nos; e, entregando-nos jovialmente a nossa imaginação, segui-la-emos por toda parte onde ela se compraza em nos conduzir. (Ibidem, p. 13, grifo do autor).

Grande preocupação em, nesses dias de reclusão e escrita, ter a companhia de um leitor imaginário que siga esse narrador em suas viagens imaginárias. Percebe-se o trabalho de argumentação desse narrador ao tentar convencer o seu leitor a ir com ele, alegando, como se vê, tratar-se de uma viagem divertidíssima, tranquila, que levará sabedoria àqueles que nela estiverem; ademais de ser superior à daqueles que vão 
a Roma ou Paris. Alega, também, que a viagem imaginária é livre, maior, e sem barreiras. Essa tentativa de convencimento da parte do narrador para com o leitor é chamada, por Eco, de acordo ficcional:

A norma básica para se lidar com uma obra de ficção é a seguinte: o leitor precisa aceitar tacitamente um acordo ficcional, que Coleridge chamou de "suspensão da descrença". O leitor tem de saber que o que está sendo narrado é uma história imaginária, mas nem por isso deve pensar que o escritor está contando mentiras. De acordo com John Searle, o autor simplesmente finge dizer a verdade. Aceitamos o acordo ficcional e fingimos que o que é narrado de fato aconteceu. (ECO, 1999, p. 81, grifos do autor).

O que ocorre em Viagem à roda do meu quarto é que, além de aceitar esse acordo e seguir viagem com o narrador imaginador, o leitor se vê obrigado a acompanhar a sequência narrativa do romance, esta que, muitas vezes, pode ser considerada inverossímil, a começar pelo seu título. De igual maneira, esse narrador é por vezes contraditório: afirma que desconhece o fato pelo qual o romance será escrito em quarenta e dois dias, mas sabemos, como já dito, que dá a entender que está preso. No posfácio do livro, Valentim Facioli comenta a esse respeito: "Desde o título do livro o leitor já sabe que está sendo "seduzido" para compartilhar de uma farsa, pois ele é contraditório em seus próprios termos: como esperar as emoções e os encantos de uma "viagem" [...] que se realiza no próprio quarto do narrador?" (FACIOLI, 2008, p. 159).
Os únicos seres com os quais esse narrador mantinha certo contato eram sua cadelinha Rosina, e seu mordomo Joannetti. Alguns capítulos são dedicados a eles, como mais à frente veremos. A viagem, por assim dizer, se dá no espaço do quarto do narrador. É um quarto pequeno, que ao longo do romance é de todo explorado. A estratégia temporal utilizada é retardada ao máximo. Percebe-se que, além de se imaginar, pouco sobra para ser contado. As pequenas ações que ocorrem são transformadas em grandes acontecimentos, merecedoras de capítulos exclusivos: o caminho da cama até a escrivaninha, assim como o tombo de uma cadeira tornam-se grandes aventuras, bem como os pequenos móveis ganham uma dimensão imensa.

Sobre a cadência da narrativa, Eco teoriza interessantemente:

Portanto, o tempo do discurso é o resultado de uma estratégia textual que interage com a resposta dos leitores e lhes impõe um tempo de leitura. [...]

$\mathrm{O}$ autor não apenas insinua ao leitor que fatos como os que se pôs a narrar de fato aconteceram, mas também mostra a medida em que aquela pequena história está arraigada na História. [...]

Não há dúvida de que às vezes uma grande quantidade de descrição, uma abundância de detalhes mínimos podem ser não tanto um artifício de representação quanto uma estratégia para diminuir a velocidade do tempo de leitura até o leitor entrar no ritmo que o autor 
julga necessário para a fruição do texto. (ECO, 1999, p. 63, 64, 65).

O que se conclui a partir do trecho citado é que, Xavier de Maistre, com o seu narrador de Viagem, tenta trazer o leitor para o mundo da ficção, para que tenha os mesmos sentimentos e passe pelas mesmas situações, dispondo do mesmo espaço de tempo que o narrador. A demora em narrar o caminho da cama até a escrivaninha, a descrição dos quadros em sua parede, o riso em um retrato, tudo consiste na estratégia de situar o leitor no mundo ficcional. A intenção é que o discurso narrativo se equivalha ao tempo de leitura, para que o leitor identifique-se com o narrador do romance que lê.

O narrador pouco confiável, digressivo e caprichoso, é sobretudo arbitrário, uma vez que as associações de ideias com que ele livremente trabalha não são as mesmas que ocorreriam com os leitores. O efeito textual constantemente de dupla face, realista e metafórico, exige que o leitor a cada momento se obrigue a compreender um sentido ou outro da representação. Estamos, assim, diante de uma "obra aberta", cujo problema central é uma convivência "conflituosa" entre narrador e leitor, pois o que está em causa é não simplesmente o sentido, mas o modo de doação do sentido. (FACIOLI, 2008 , p. 160, grifos no original).

O que Facioli afirma neste trecho pode nos levar a pensar um pouco mais a fundo sobre o estado de melancolia em que se encontra o narrador de Viagem. Recordando-nos do pacto ficcional de Eco, podemos afirmar que o leitor, mesmo que "assinando", por sua vez, este termo de ficcionalidade, pode não ter as mesmas sensações e reações de um leitor ideal, por assim dizer, que é construído ou projetado pelo narrador-autor, deste romance. O que faz com que este narrador se comporte de maneira autoritária durante praticamente toda a narrativa. Tal comportamento pode ser entendido como uma possível reação consequente da melancolia que sente por estar preso por quarenta dias no seu quarto, talvez desesperado e com medo que a sua única companhia constante, o leitor, o abandone.

Continuando este raciocínio, o leitor pode não ver graça, por assim dizer, na ideia proposta pelo narrador de de Maistre, além de talvez duvidar da sua palavra ao afirmar, por várias vezes, que as viagens imaginárias são melhores e mais proveitosas do que as viagens físicas, "reais". O que se nota é que nem mesmo o narrador consegue se sustentar na crença desta ideia durante todo o tempo, sendo este comportamento interpretado como um sinal de melancolia e desespero, por tentar convencer o leitor de algo que não está claro para si mesmo.

Sobre o leitor, ao mesmo tempo em que se faz necessário para a construção do romance, como se viu com os trechos citados na insistência do narrador para que viajem juntos, ele não é levado tão a sério. $O$ narrador em primeira pessoa não consegue se manter amável por muito tempo e, por muitas vezes, tece discursos autoritários e mal fundamentados, bem como se justifica das más ações que pratica, na intenção de que o leitor o compreenda e inocente; considerando o fato de que esse narrador já conta 
com o julgamento do leitor a seu favor antes de qualquer coisa. Pretensioso, o narrador exige a presença do leitor durante todo o tempo, no intuito de julgar suas ações, mas sempre o favorecendo; pedindo sua opinião somente para concordar com ele: "E, contudo, leitor razoável, vede quão pouca razão tinham esses homens, e apossai-vos bem, se puderdes, da lógica que passo a vos expor." (MAISTRE, 2008, p. 14).

Alfredo Bosi, em um de seus estudos sobre Machado de Assis, faz uma leitura crítica acerca de Memórias Póstumas de Brás Cubas, romance que leva muito de Viagem à roda do meu quarto, como todos sabemos. Tal leitura, sobre o narrador, cabe perfeitamente neste romance que nos propusemos a analisar:

O eu que narra o acontecido não está só. Presume que terá algum leitor ou leitora e pressente que esse outro, dotado de "alma sensível", poderá censurá-lo pelo seu cinismo - palavra forte, mas dita com todas as letras. É deste outro imaginado e virtual que vem $o$ juízo ético, mas é o eu narrador que o desentranha e o invoca e obriga-se a escutá-lo e a transmitir-nos a sua voz. (BOSI, 2006, p. 11, grifo do autor).

Sendo pensado e construído pelo narrador, o leitor exerce um papel instável na obra de de Maistre, pois o próprio narrador se encontra nesta situação. Como afirma Rosset: "a intensidade da alegria pode ser medida segundo a quantidade de saber trágico que ela implica" (ROSSET, 1998, p. 9). Por vezes o narrador tenta mascarar sua melancolia por meio do humor e de um falso contentamento em escrever estas viagens, mas sabemos que a narrativa só é escrita porque ele se encontra encarcerado em seu quarto, sendo forçado a fazer alguma coisa para passar o tempo em que está preso. Tal máscara por vezes funciona, mas de forma osciladora. O narrador consegue ser cômico em alguns momentos, mas logo essa alegria se transforma em melancolia, e a máscara cai, por assim dizer, mostrando um narrador mais preocupado com o seu sentimento de tristeza e falta de liberdade, que com o leitor da sua história. "Aquele que procura impedir o acontecimento temido se torna o agente de sua própria desgraça, e o destino, por elegância ou por preguiça, delega aqui às vítimas a responsabilidade de fazer todo 0 trabalho no seu lugar." (ROSSET, 1998, p. 24).

Ao mesmo tempo em que percebemos essa dupla relação com o leitor, ora amável, ora pedante, o narrador, como dito anteriormente, se relaciona com mais dois seres: a cadelinha Rosina, e o criado Joannetti. Com este, o narrador possui a desconfortável sensação de impotência quando visto que sua superioridade em relação ao mordomo é relativa. Quando forçada a mostra à superioridade intelectual do narrador, a atitude humilde do empregado coloca-o em posição de vantagem, deixando-o superior ao próprio patrão. Com isso, o narrador, talvez em estado de compaixão, talvez no intuito de se redimir reconhecendo a superioridade do mordomo, tira as atenções de si e volta-as a ele, apontando-as ao leitor.

"Fora!", disse-lhe [a Joannetti] eu um dia, "já é a terceira vez que lhe mando comprar uma escova! Que cabeça! Que animal!” Ele não 
respondeu uma palavra: já na véspera não tinha respondido nada a outra descompostura igual. "Ele é tão exato!", dizia eu; não concebia nada daquilo. "Vá buscar um pano para me limpar os sapatos”, disse-lhe furioso. Enquanto ele ia cumprir a minha ordem, arrependia-me de tê-lo assim maltratado. [...] "Joannetti", disse-lhe, retirando o pé, "você tem dinheiro?" Um meio sorriso de justificação apareceu-lhe nos lábios ao ouvir essa pergunta. "Não, senhor; há oito dias que não tenho um vintém; gastei tudo o que tinha nestas pequenas compras." "E a escova? Foi, sem dúvida, por causa dela?" Tornou a sorrir. Ele podia ter dito a seu patrão: "Não, eu não sou um cabeça-oca, um animal, como o senhor teve a crueldade de chamar ao seu fiel criado. Pague-me 23 libras, 10 soldos e 4 dinheiros que me deve e eu lhe comprarei a escova." Antes quis deixar-se maltratar injustamente do que expor o seu patrão ao rugido de sua cólera. (MAISTRE, 2008, p. 37, grifos do autor).

“Bela atitude do mordomo!” É o que o narrador quer que o leitor pense, já que no final do capítulo anterior, antes de narrar o acontecimento citado, ele diz: "A sua conduta, nessa ocasião, me interessou muito, e fê-lo penetrar mais fundo no meu coração. Terá sem dúvida um lugar também no do leitor..." (Id., p. 36). O que prova continuar sendo autoritário, pois não conta com a possibilidade da não comoção dos leitores com o mordomo, como visto. Porém, com os quarenta e dois dias de prisão domiciliar, sem contato com outras pessoas e experiências, o narrador começa a prestar aten- ção nas coisas que o cercam. A atitude do mordomo mexeu com o seu coração autoritário, e mostrou que a superioridade não se dá apenas pelo conhecimento. Ao longo desse tempo viajando pelo quarto, o narrador cresceu como pessoa, e tornou-se mais humano. Sentimento semelhante tem pela cadelinha Rosina:

A minha querida Rosina, que nunca me ofereceu serviços, presta-me o maior serviço que se possa prestar à humanidade: ela me amava outrora, e me ama ainda hoje. Por isso, não receio dizê-lo, eu a amo com uma porção do mesmo sentimento que consagro aos meus amigos.

Digam o que quiserem. (Ibidem, p. 35).

Esse trecho é o único momento do livro em que o narrador não se preocupa com julgamentos. Durante todo o romance ele se esforça para que o leitor o julgue de maneira a sempre favorecê-lo. Quando comete alguma ação injusta, como no caso do criado Joannetti, mostra arrependimento, e dá destaque a essa segunda pessoa, declarando sua superioridade em relação a si mesmo. Mas aqui isso não acontece. Não há esforço do narrador para que o leitor o compreenda, nem fique ao seu lado, concordando com o sentimento de amor a um animal na mesma medida em que ama os amigos. O próprio narrador constata: "E eis como, na minha viagem, vou recebendo lições de filosofia e de humanidade do meu criado e do meu cão.” (DE MAISTRE, 2008, p. 52). Sandra Stroparo, concluindo a explanação acerca do criado e da cadelinha, assim escreve: 
Rosine, a cachorrinha poodle do narrador, serve para uma explanação sobre o amor dos homens pelos animais - e vice-e-versa. O criado Joanetti é motivo para boas reflexões sobre as relações humanas, que não escondem muitas vezes a prepotência e a falta de modos do "patrão". (STROPARO, 2009, p. 10).

Relação importante do narrador é também com os livros. Estes despertam a imaginação, e sem eles o número de viagens imaginárias que faria o leitor/narrador seria muito restrito. Já ao final do romance, o narrador discorre sobre sua relação com as personagens da ficção:

Como se não me bastassem os meus males, ainda partilho voluntariamente os de mil pessoas imaginárias, e o sinto com tanta intensidade como os meus próprios: quantas lágrimas não derramei por motivo daquela infeliz Clarisse e pelo apaixonado de Carlota!

Mas, se procuro desse modo aflições fingidas, em compensação encontro, nesse mundo imaginário, virtude, bondade e desinteresse como ainda não achei reunidos no mundo real em que existo. [...]

Quando tenho chorado e amado bastante, procuro um poeta qualquer e parto de novo para outro mundo. (MAISTRE, 2008. p. 63, 64).

A ficção é muito mais cômoda que o mundo real, é claro. Nela nos sentimos absolutamente no controle das situações, e confortáveis em nossa posição externa aos fatos. É ela quem nos permite viajar pelos bosques imaginativos, a montar enredos e sonhos criativos. "Às vezes se diz que o iludido não vê: ele está cego, cegado. É inútil a realidade se oferecer à sua percepção: ele não consegue percebê-la, ou a percebe deformada, tão completamente atento que está apenas aos fantasmas de sua imaginação e de seu desejo." (ROSSET, 1998, p. 14). Este trecho de Rosset se aplica ao narrador de Viagem, mas de maneira contrária. O narrador deste romance quer ser o iludido, mas não consegue. Ele quer se tornar cego, quer não perceber a realidade. E tenta assim parecer para o leitor. Ele quer enxergar o que escreve, fantasiando seu encarceramento com uma prazerosa viagem imaginária. Mas não consegue convencer o leitor por todo o tempo, e também a si mesmo.

Outra peculiaridade desse narrador pretensioso é sua visão crítica na construção de teorias sobre as coisas. Como sabemos, seu autoritarismo é constante. Não se faz presente somente na relação com o leitor e com o mordomo, mas também no seu pensamento sobre o mundo. No capítulo VI do romance, o narrador expõe uma teoria de sua autoria sobre a alma e a besta:

Percebi, por diversas observações, que o homem é composto de uma alma e de uma besta. - Estes dois seres são absolutamente distintos, mas de tal modo estão encaixados um no outro, ou um sobre o outro, que é preciso que a alma tenha uma certa superioridade sobre a besta para estar em condição de distinguir-se. [...]

Percebe-se bem pelo alto que o homem é duplo; mas isso porque, diz-se, ele é 
composto de uma alma e um corpo; e acusa-se este corpo de não sei quantas coisas, mas bem mal a propósito com certeza, pois ele é tão incapaz de sentir como de pensar. É a besta que devemos incriminar, esse ente sensível, perfeitamente distinto da alma, verdadeiro indivíduo, que tem a sua existência separada, os seus gostos, as suas inclinações, a sua vontade, e que não está acima dos outros animais senão por ser melhor educado e provido de órgãos mais perfeitos. (MAISTRE, 2008, p. 19, grifo do autor).

Vista a exposição da teoria, o que concluímos é que esta foi criada pela melancolia de estar trancafiado no próprio quarto durante quarenta e dois dias sem poder sair. Por que "besta" ao invés de corpo? Pelo desgosto, pela raiva e agonia de se estar preso. A proposta, no início do livro, é de se fazer uma viagem pela imaginação. O narrador insinua que este tipo de viagem fará rir quem foi a Roma ou Paris, pela sua superioridade em relação a essas, mas, ao longo do romance, percebe que pouco adianta viajar sem sair do lugar. O sentir, o ver, o estar, fazem-se, nessa ocasião, mais ricos que o imaginar. O narrador, no entanto, não pode deixar explícito que a viagem apenas da alma, utilizando os termos da teoria, seria em vão, pois a propaganda que fez ao leitor foi muito bem articulada e argumentada. Ele tenta fazer valer seu julgamento de que a alma pode sobreviver sem a besta, mas falha com as próprias tentativas. "São baldados os esforços; é preciso abandonar a partida e descansar aqui bem contra a vontade: um alto militar." (Ibidem, p. 28). Facioli, sobre isso, argumenta:
Para o narrador são sempre vãs as tentativas de independência da inteligência em relação às exigências da besta. O efeito é cortante em humor, ironia e comicidade. [...]

A liberdade possível na prisão, alcançada mediante a imaginação e a inteligência, não é substituto possível para a liberdade que os homens devem gozar na convivência com os outros homens, na vida em sociedade. (FACIOLI, 2008. p.161, 162).

A teoria da alma e da besta, como se viu, foi criada pela impotência da satisfação do narrador ao viajar somente pela imaginação, sem sentir no corpo, ou na besta por assim dizer -, as marcas da viagem. Mas há outras formas em que essa melancolia se manifesta. Em quase todos os capítulos, como o próprio narrador assume, os finais são menos alegres que os começos. O capítulo pode tratar de um retrato, o que aciona a lembrança do narrador para um passado romanticamente infeliz, ou faz lembrá-lo de um amigo que morreu, e o capítulo toma outro rumo, que é o da homenagem. $\mathrm{O}$ ar rude transforma-se em singelo, devido à mudança de sentimento do narrador por conta da sua falta de controle dos acontecimentos. As noites, os dias, as noites, os dias, as horas... o tempo leva à reflexão acerca do confinamento que tem de suportar nesses quarenta e dois dias e, consequentemente, aflora a melancolia.

Para demonstrar a melancolia em não poder sair de seu quarto, além dessa teoria, o narrador fala das horas: "As horas então 
deslizam sobre nós, e caem em silêncio na eternidade, sem nos fazer sentir a sua triste passagem." (MAISTRE, 2008, p.16). Cabe lembrar que a intenção do narrador não é de ser melancólico, mas a tristeza se faz tão grande que fica evidente em meio aos seus discursos que nem ele próprio consegue controlá-la. Por vezes está falando sobre determinado assunto, e quando se dá conta a melancolia já se faz presente, invadindo a narração. No início do romance, o narrador propõe uma viagem divertida. Assim o tenta fazer. Por vezes força um discurso humorístico, mas não é feliz em totalidade.

Eu tinha enfim chegado bem perto da minha secretária, tanto que, estendendo o braço, me seria possível tocar no ângulo mais próximo de mim, quando estive mesmo a ponto de ver destruir-se o fruto de todos os meus trabalhos e de perder a vida. - Deveria passar em silêncio pelo acidente que me aconteceu, para não desanimar os viajantes, mas é tão difícil voltar-se na liteira de que me sirvo que, teremos de concordar, é preciso ser infeliz até o último ponto - tão infeliz como eu sou - para correr semelhante risco. Encontrei-me estendido no meio do chão, completamente caído e decaído; e isso tão depressa, tão inopinadamente, que estaria tentado a pôr em dúvida a minha desdita se um zunido na cabeça e uma violenta dor no ombro esquerdo não me tivessem demonstrado sua autenticidade com demasiada evidência. (MAISTRE, 2008, p. 50-51).

Sérgio Rouanet constata que o humor serviu para temperar a melancolia do narra- dor, camuflando-a: "essa operação de camuflagem começa com o título, forma absurda, e por conseguinte cômica, de exprimir uma experiência que nada tinha de cômica, a privação da liberdade." (ROUANET, 2007, p. 212). Alfredo Bosi, ainda no ensaio sobre Brás Cubas, analisa a presença do humor no romance, e esta análise, como a outra dele aqui exposta, faz-se muito pertinente se lida com o olhar direcionado à Viagem. Cabe citá-la:

Humor cuja "aparência de movimento" feita de piruetas e malabarismos mal disfarça a certeza monótona do nada que espreita a viagem que cada homem empreende do nascimento à hora da morte.

Humor que decompõe as atitudes nobres ou apenas convencionais, pondo a nu as razões do insaciável amor-próprio, das quais a vaidade é o paradigma e a veleidade o perfeito sinônimo.

Humor que mistura a convenção e o sarcasmo na forma de máximas paradoxais. (BOSI, 2006, p. 29).

Como se vê, o humor presente em Viagem à roda do meu quarto, interiormente, possui características que o aproximam da melancolia, em um processo de autocomplementação. A ideia que se tem é se não houvesse melancolia, esse humor seria diferente, aproximando-se do singelo, e não do irônico e sarcástico. É um riso triste e sofrido. Entretanto, as pílulas filosóficas mais poéticas e melancólicas são referentes ao tempo. Todo o livro, em suas reflexões, bem como por trás da máscara 
cômica e humorística, é melancólico. $\mathrm{Na}$ medida em que a história avança, o narrador vai se tornando sensível. Passa a olhar com compaixão as atitudes do criado, da cadelinha, bem como reflete sobre seu passado e o que nele julga importante. Apesar de tentar dar um tom cômico ao romance, narrando tombos, cenas ironicamente graciosas, o riso se esconde e quem ganha espaço é a tristeza, como muito já dito. Sobre isso, o próprio narrador discorre na obra:

Não sei como isso me acontece; há algum tempo que os meus capítulos acabam sempre num tom sinistro. Em vão, ao começá-los, fixo meus olhares em algum objeto agradável em vão embarco pela calmaria, logo caio numa borrasca que me faz soçobrar. (MAISTRE, 2008, p. 44).

- É talvez porque a alma, inundada hoje de ideias negras e de quadros dilacerantes, encontra por toda parte assuntos de tristeza, como um estômago viciado converte em venenos os alimentos mais sãos. (Ibidem, p. 56).

O narrador de Viagem à roda do meu quarto, por fim, descobriu, além da duplicidade do homem contida na teoria da alma e da besta, um outro eu escondido dentro da prepotência engolida pela prisão domiciliar. As experiências vividas nesse período o fizeram crescer interiormente, a tornar-se alguém melhor. Fato curioso é que todas as vivências foram realizadas através da imaginação e, consequentemente, da reflexão.

O espelho representa ao viajante sedentário mil reflexões interessantes, mil observações que o tornam um objeto útil e precioso. [...]

Sempre imparcial e verdadeiro, um espelho patenteia aos olhos do espectador as rosas da mocidade e as rugas dos anos, sem caluniar e sem lisonjear ninguém-é, entre todos os conselheiros dos grandes, o único que lhes diz constantemente a verdade. (Ibidem, p. 48, 49).

Esse trecho se dá no momento de descrição dos quadros da parede do seu quarto, quando, de repente, o narrador depara-se com seu espelho. O que ocorre, porém, é que suas conclusões não nos são reveladas, e para suprimir essa falta com o leitor, o narrador teoriza sobre a invenção de um espelho moral, olvidando-se de como se vê diante dele, tentando manter o autoritarismo em sua voz. Outra leitura desse capítulo se dá através da metáfora do espelho. Valentim, acerca disso, constata:

Primeiramente, parece-me que a concepção artística que informa esses textos transita da representação literária entendida como "espelho da vida" - vinda da tradição clássi$\mathrm{ca}$ - para aquela outra que a entende como "lâmpada", isto é, iluminadora e reveladora de dimensões obscuras, inesperadas, da realidade social e do ego. A convivência entre a representação realista e a metafórica. (FACIOLI, 2008, p. 159-160).

O espelho, tomando como base a fala de Valentim, aproximando-se da intenção da utilização da técnica temporal, serve também para representar esse mundo 
ficcional com equivalência ao mundo real. O narrador de Viagem à roda do meu quarto se encontra na mesma situação que o leitor de romances. O leitor, ao adentrar na ficção, vive o mundo ficcional, assemelhando-o ao real, mas, ao mesmo tempo, sabe diferenciá-los. O narrador, preso nesse mundo de imaginação, ficcional, por assim dizer, está impedido de encontrar o seu mundo real, fora do quarto, que permitiria sensações de tato e experiências vividas e interativas. "Com efeito, o destino de toda coisa existente é denegar, por sua própria existência, qualquer outra forma de realidade." (ROSSET, 1998, p. 43).

A insistência do narrador para que o leitor o acompanhe, mascarando o medo da sua desistência do mundo de ficção, e volte para o mundo real, pode ser lida, também, como o próprio medo (do narrador) de desistir desse mundo de imaginação nesses quarenta e dois dias, fazendo com que sua alma se entregue à besta, e à razão. Como dito em passagem anterior, a ficção é muito mais confortável do que o mundo real. Isso vale também para os personagens da ficção que se veem dentro de outra ficção. $O$ espelho proporciona a reflexão e razão. O narrador, ao olhar para si mesmo, percebe que o seu eu foi dividido. Há o eu do mundo real, aquele que vivia fora do quarto, e o eu que construiu dentro do quarto, a partir da sua imaginação e experiências que proporcionaram a melhora dos seus sentimentos por conta da exposição dos mesmos ao leitor. Ao fim do romance, o narrador o constata:

Contudo, nunca percebi com mais clareza o quanto sou duplo. - Enquan- to lastimo a perda dos meus gozos imaginários, sinto-me consolado pela força: arrasta-me um poder secreto; diz-me ele que tenho necessidade do ar do céu, e que a solidão se parece com a morte. [...]

Ó, minha besta, minha pobre besta, toma conta de ti! (MAISTRE, 2008, p. 84).

A melancolia de se estar preso em seu quarto, sem oferecer prazeres à besta, toma outra direção, e volta-se à alma. Sandra Stroparo destaca o "embate entre o conforto intelectual do confinamento e o desejo pelo mundo de fora, da atividade, da vida. A oposição clara entre o que se 'pensa' sobre o mundo e como o mundo de fato se apresenta." (STROPARO, 2009, p. 18). É a fiç̧ão dentro da ficção, e aproximação do narrador com o leitor, no que diz respeito à ficção e realidade, mesmo que realidade ficcional.

Por fim, conclui-se que, a partir de todos os comentários relativos ao livro, Xavier de Maistre conseguiu fazer das suas viagens imaginárias um romance inovador e reflexivo. "Pela imaginação, o narrador se move num espaço infinito e no tempo da eternidade." (ROUANET, 2007, p. 44).

Máximas ora atrevidas, ora desenganadas, teorias extravagantes, anedotas à primeira vista sem ligação com o contexto, digressões de vário tipo, ziguezagues com quebras da ordem temporal e espacial, interlocuções frequentes e às vezes petulantes com o leitor [...].

A presença enfática do narrador; a técnica da composição livre, que dá 
ao texto a sua fisionomia digressiva e fragmentária; o uso arbitrário do tempo e do espaço; a interpretação de riso e melancolia. (BOSI, 2006, p. 22, 24).

Todos os aspectos neste artigo estudados e no trecho acima resumidos constroem o romance de Xavier de Maistre. O narrador autoritário, ao longo do livro, se descobre mais sensível e menos prepotente. A teoria da alma e da besta mostra a duplicidade do homem que, quando adquire a consciência disso, pode descobrir sua parte boa e má, além de diferenciar o imaginar de o sentir. A melancolia de se estar preso por quarenta e dois dias faz descobrir o grande valor de seres que, em momento de liberdade, não teriam oportunidade de se mostrarem superiores em muitos sentidos. O riso mascarado, escondendo a tristeza da dor de se perder a liberdade. O tempo como possibilidade de reflexão sobre como ser e pensar. O olhar para dentro de si através do espelho, e perceber o conforto de uma ficção. Ademais da forma como o romance se dá, digressivo, com cadências diferentes, imitando o recurso imagético, rápido, desfragmentado, se comparado às ações corporais. Por fim, a mimese que relaciona os dois mundos: ficção e realidade, e as diferenças sensoriais que estes possuem. É a soma das estratégias de construção do romance que mostra a melancolia do riso nas viagens imaginárias de um narrador, e faz com que Viagem à roda do meu quarto seja a viagem de cada um dos leitores, quando adentram pelos bosques da ficção.

\section{REFERÊNCIAS}

BOSI, Alfredo. Brás Cubas em três versões. São Paulo: Companhia das Letras, 2006. ECO, Umberto. Seis passeios pelos bosques da ficção. São Paulo: Companhia das Letras, 1999.

FACIOLI, Valentim. Posfácio "O romance da contraviagem". In: MAISTRE, Xavier de. Viagem à roda do meu quarto. São Paulo: Estação Liberdade, 2008.

MAISTRE, Xavier de. Viagem à roda do meu quarto. São Paulo: Estação Liberdade, 2008.

ROSSET, Clement. O real e seu duplo: ensaio sobre a ilusão. Porto Alegre: L\&PM, 1998.

ROUANET, Sérgio Paulo. Riso e melancolia. São Paulo: Companhia das Letras, 2007.

STROPARO, Sandra. Nota sobre a tradução. In: MAISTRE, Xavier de. Viagem em volta do meu quarto. São Paulo: Hedra, 2009.

Recebido para publicação em 20 ago. 2012. Aceito para publicação em 28 jan. 2013. 